\title{
Comparative Experimental Study on the Filter of Waste Car-washed Water Based on the Technology of the Flexible Self-feedback Fiber Filtration
}

\author{
Wensheng Lyu ${ }^{1, a}$, Zhaoxia Yin ${ }^{2, b^{*}}$, Ye Lyu ${ }^{3, c}$ and Pengchun $\mathrm{Hu}^{1, d}$ \\ ${ }^{1}$ Automotive and Architectural Engineering College of Beihua University Jilin Jilin China 132013 \\ ${ }^{2}$ Foreign Language College of Beihua University Jilin Jilin China 132013 \\ ${ }^{3}$ College of Foreign Languages in Northeast Forestry University Harbin Heilongjiang China 150000 \\ alwskytd@126.com, b941846596@qq.com, c2503086882@qq.com, d2844311831@qq.com \\ *The corresponding author
}

Keywords: Fiber filter; Flexible self-feedback; Waste car-washed water; Quartz sand

\begin{abstract}
Comparative experiments between the technology of the flexible self-feedback fiber filtration and quartz sand filtering confirm that the fiber filtering for waste car-washed water is much better than the application of quartz sand. In the condition of higher raw water turbidity and two times fiber filtration rate compared with the rate of quartz sand, the operating cycle of fiber filtration is longer than the quartz sand, and the interception capability is 2 times than quartz sand. The filtered water turbidity can be controlled at 5.0 NTU or less, and the average turbidity is $29.5 \%$ higher than the quartz sand, the average COD removing rate is $67.1 \%$ higher than the quartz sand. But for LAS, both of removing rates are not very high with little difference.
\end{abstract}

\section{Introduction}

At present, the types of the recycling of waste car-washed water treatment equipment are various; meanwhile the processes, controlling methods and recovery levels are different. Currently, the reused treatment methods of waste car-washed water are the traditional degreasing, filtration and other simple physical treatment, such as membrane filtration, physical-chemical treatment, electrolysis, membrane bioreactor and several combinations of methods, based on different processes in which produce a variety of different treatments and reused devices. [1]

There are some limitations on the above several wastes car-washed water treatment processes, especially in the key aspects of sewage treatment filtration process, the low filtration rate, the poor effect, and the large equipment. But the fiber filtration method takes prominent advantage from this aspect. [2] To solve these problems, the researchers of this project carry out an experimental study on application of fiber filtration technology to deal with waste car-washed water

Fiber Filtration Technology Introduction. Fiber Filtration Technology selected flexible materials - polypropylene fiber filament as a filter ,[3]the relevant technical indicators are: (1) Filtration: After a good coagulation of raw water turbidity $\leq 20 \mathrm{FTU}$, the filtered water turbidity is always $\leq 2$ FTU.The rate of water removal up to $99 \%$ can significantly removed the bacteria, viruses, macromolecules and other organic impurities;(2) Filtration speed: $20 \mathrm{~m} / \mathrm{h}-50 \mathrm{~m} / \mathrm{h}$, is the $3-5$ times of quartz sand filtration rate;(3) Interception capacity: $5-10 \mathrm{Kg} / \mathrm{m}^{3}$ (filter), is $2-4$ times of the traditional filter material capacity;(4) Area: the same amount of water, covering the traditional filter 1/3-1/2 only; (5) Water consumption: 1-3\% of the cycle water, under normal circumstances available raw water;(6) Fiber filter chemical stability, filtration process does not produce any chemical reaction, continuous service life of not less than 10 years, there is no run material and the phenomenon of compaction.[4]

\section{Test Equipment and Methods}

Test Equipment. Pool: for coagulation sedimentation. 
A total of 2 groups of filter columns, are made of transparent plexiglass, the diameter of which is $50 \mathrm{~mm}$. The operating process chooses the way of the upper water in and the bottom of the water out.

Sand filter: sand filter column filled with a high degree of $1100 \mathrm{~mm}$, the upper layer of $400 \mathrm{~mm}$ thick, $0.3 \mathrm{~mm}$ diameter quartz sand, the lower thickness of $700 \mathrm{~mm}, 0.5 \mathrm{~mm}$ diameter quartz sand. The average particle size of about $5 \mathrm{~mm}$ gravel is applied as a supporting layer, gravel filling height of 20mm. [5]

Fiber filter column: fiber filter weighs 408g, puffing degree is 20\%.[6] Fiber filter technical parameters are in Table 1,fiber bundle installation for the bottom is fixed, the top is free. [7]

Table 1 fiber filter element main technical parameters[8]

\begin{tabular}{cccccc}
\hline Material & density & length & weight & $\begin{array}{c}\text { Volume ratio } \\
\text { filament diameter }\end{array}$ & $\begin{array}{c}\text { puffing } \\
\text { degree }\end{array}$ \\
\hline $\begin{array}{c}\text { Polypropylene } \\
\text { filament }\end{array}$ & $0.91\left[\mathrm{~g} / \mathrm{cm}^{3}\right]$ & $1.3[\mathrm{~m}]$ & $160\left[\mathrm{~kg} / \mathrm{m}^{3}\right]$ & $50[\mu \mathrm{m}]$ & $20 \%$ \\
\hline
\end{tabular}

Test Water Quality. The experiment is about the small car wash which is waste water from car washer, the water quality index are following.

Turbidity: $346 \mathrm{NTU}$, CODcr: $185 \mathrm{mg} / \mathrm{L}$, LAS (Anionnic surfactant):5.8mg/L, $\mathrm{pH}$ is 7.7 , water temperature: $14^{\circ} \mathrm{C}$.

Analytical Method. Turbidity: using instrument HACH2100N, COD: The potassium chromate method,

LAS: methylene blue spectrophotometer method test.

Test Method. Related research indicates that treatment for reuse of car washing which selected PAC as the coagulant good effect. The best quantity of reagent is $80 \mathrm{mg} / \mathrm{L}$. The mixing time is five minute, settling time is 15 minutes.[9]After using the above method of coagulating sedimentation, test the turbidity, CODcr, LAS and water quality index.

After comparing the treated water with coagulant and untreated separated into sand filtration column and fiber filtration column, the speed of sand filtration column is $8 \mathrm{~m} / \mathrm{h}$, the speed of fiber filtration column is $16 \mathrm{~m} / \mathrm{h}$. The test method is to get the sample from the sand and fiber filtration column per hour. Test the major index is turbidity, CODcr, anionic detergent and the filter materials is out of use and then stop the experiment. The waste of carwash during the washing contains little oil material, and our life non-drinking water (CJ/T 48-1999) has no related regulations. So the text cannot test the oil material.

Table 2 waste the carwash before and after water quality index

\begin{tabular}{lll}
\hline Item & Wastewater from car washer & Reuse water quality \\
\hline $\mathrm{COD}_{\mathrm{Cr}}[\mathrm{mg} / \mathrm{L}]$ & $100-600$ & 50 \\
Turbidity $[\mathrm{NTU}]$ & $50-300$ & 5 \\
$\mathrm{pH}$ & $5.5-8$ & $6.5-9.0$ \\
Grease $[\mathrm{mg} / \mathrm{L}]$ & $2-9$ & \\
LAS $[\mathrm{mg} / \mathrm{L}]$ & $1.5-3$ & 0.5 \\
\hline
\end{tabular}

\section{Test Results and Analysis}

Coagulant Water Quality. Turbidity, CODcr and LAS are 47.47 NTU, $107.73 \mathrm{mg} / \mathrm{L}$ and 4.46 $\mathrm{mg} / \mathrm{L}$ respectively.

Comparative Analysis of Filtering Effect between Silica Sand and Fiber. Turbidity of effluent: After comparing the treated water with coagulant and untreated separated into sand filtration column and fiber filtration column, which continuous operation 8hours. You can see lots of impurities left on the silica sand and fiber. The water quality deteriorated obviously and the surface 
of the fiber color turns to tawny. But the water quality has no obvious variation. Silica sand and fiber material turbidity of effluent index as the Fig. 1.

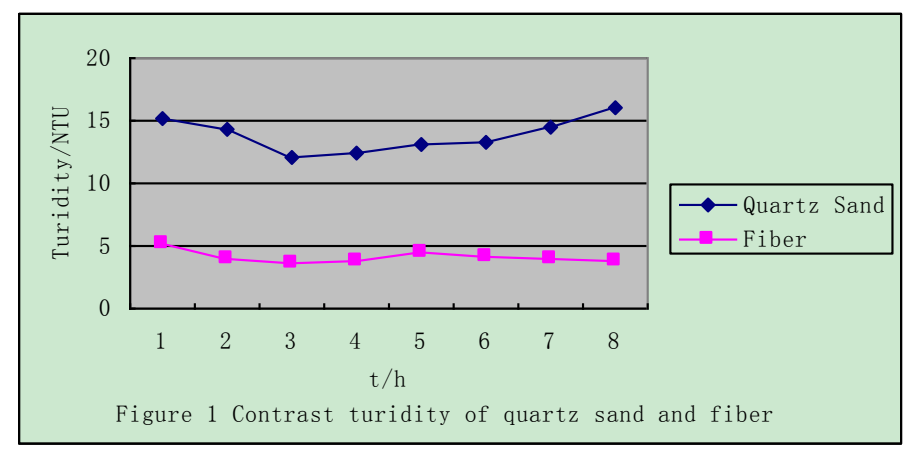

The average turbidity of sand and fiber material is $13.85 \mathrm{NTU}$ and $3.96 \mathrm{NTU}$.It is clear that the fiber material is two times than the turidity of effluent of the silica sand, which is for the less than five NTU turbidity of life non-drinking water qualified standard. The cycle of operation is long to the silica sand. At the same time, the holding filth capacity is two times than the silica sand.

COD: The average indexes of CODcr are $59.9 \mathrm{mg} / \mathrm{L}$ and $76.9 \mathrm{mg} / \mathrm{L}$ filtered by fiber and quartz sand. Fiber filter is better than quartz sand with the removal efficiency at 2 times of COD. The reason is that the fiber filter has a higher specific surface area. Its retention, adsorption and interception performance is strong. It can intercept the micro flocculation in the water effectively, thus getting better water quality.[10] As seen in Fig. 2.

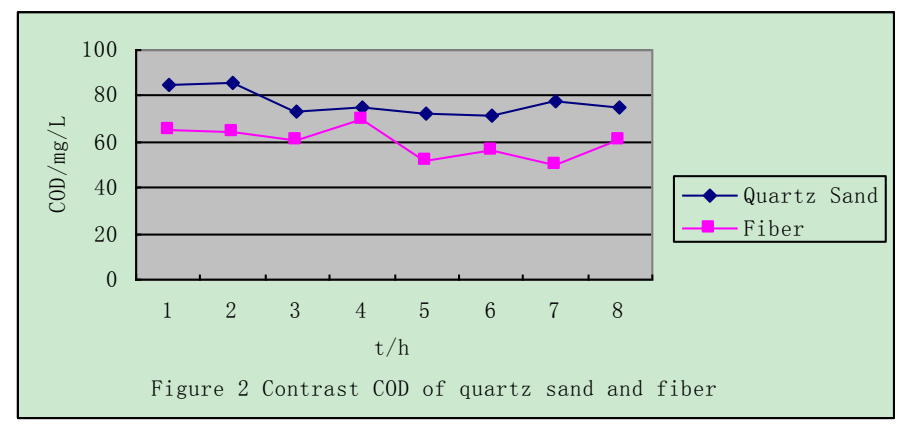

LAS: The average indexes of LAS are $4.09 \mathrm{mg} / \mathrm{L}$ and $4.15 \mathrm{mg} / \mathrm{L}$ filtered by fiber and quartz sand. The LAS in fiber filter material at 2 times filtration rate is higher than quartz sand. But the treatment effects of fiber and quartz sand are not obvious. As seen in Fig. 3.

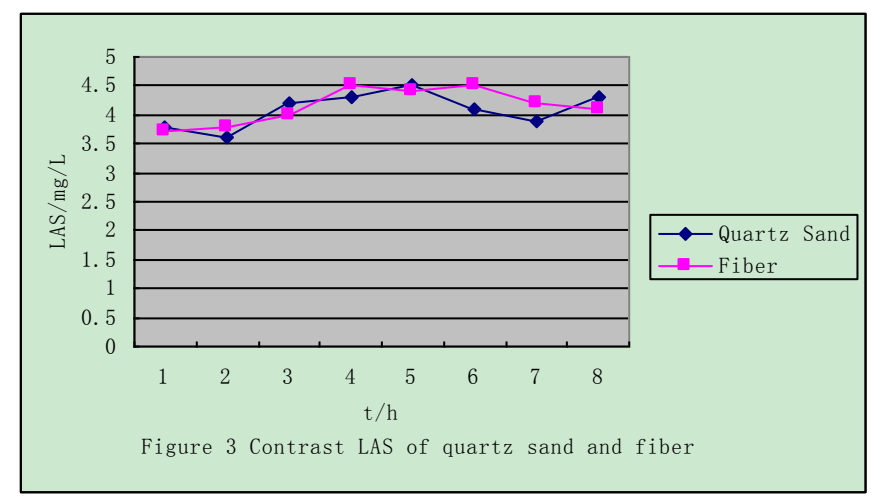

In 8 hours operating cycle and under the condition of fiber filter efficiency is two times of quartz sand, the average removal efficiencies of filtration turbidity of fiber and quartz sand are $91.7 \%$ and $70.8 \%$, the average removal efficiencies of CODcr are $47.8 \%$ and $28.6 \%$ and the average removal efficiencies of LAS are $7.0 \%$ and $8.3 \%$ after coagulation clarification of the raw water. The removal 
efficiencies of turbidity of fiber and quartz sand are both higher. Fiber filter material is higher than quartz sand of $29.5 \%$, so it has obvious advantages. For COD, the removal efficiencies of fiber filter material is higher than quartz sand of $67.1 \%$, so it is better than quartz sand obviously. For LAS, both of them have some removal effect, but the removal efficiency is not high, and they have no significant differences. As shown in Fig. 4.

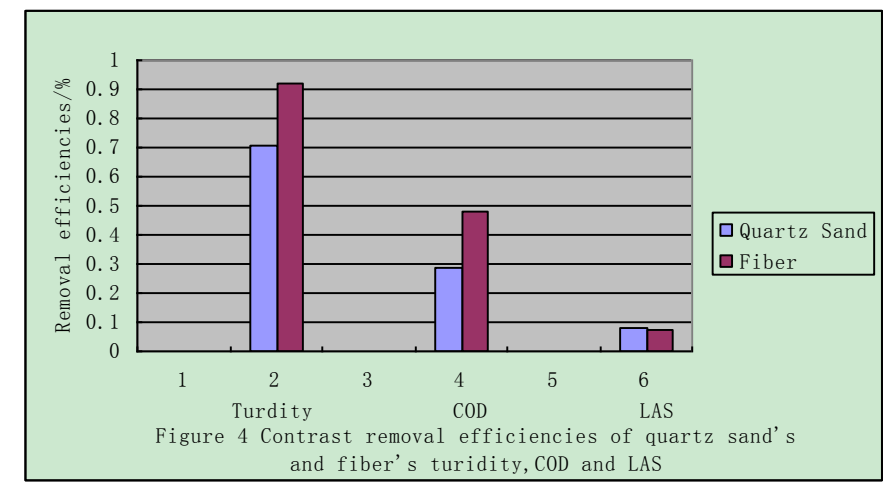

\section{Conclusion}

Fiber filter material can deal with waste car-washed water. And effluent quality is better than filtration of quartz sand. In the case of high turbidity of raw water, filtered water turbidity can be controlled below 5.0 NTU.

Under the condition of fiber filter efficiency is two times higher than quartz sand, its operating cycle is longer than quartz sand and its pollutant catching capacity is more than 2 times of quartz sand.

Fiber filter is obviously better than quartz sand with the removal efficiency of COD. Under the condition of 2 times filtration rate, the average removal efficiency is higher than quartz sand of $67.1 \%$.

The removal efficiencies of fiber filter and quartz sand on LAS are not high and the following-up process requires targeted treatment measures.

Therefore, fiber filter and quartz sand filtration have obvious advantages compared with the effluent index and the filtration period. At the same time, because the speed of the fiber filter is fast, its equipment covers an area less than one-half of the sand filter. And the filter material is long lasting; therefore, it is good for realizing the goal of miniaturization, reliable operation, low cost and high efficiency of the waste car-washed water treatment device.

\section{Acknowledgements}

This project is the scientific and technology research for the provincial department of education in Jilin. Item No.138, 2015.

\section{References}

[1] Y.H. Zhou and H.R. Hua, Research on Waste Water Treatment and Reuse Equipment for Car Washing, Renewable Resources and Recycling Economy, Vol.6 (2013) No.9,P. 41-44.(In Chinese)

[2] Y.F, Jiang, L. Wang, B.Z, Wang etal, A study on reclamation of secondary effluent by fiber filtration. Techniques and Equipment for Environmental Pollution Control, Vol.6 (2005) No.12,P. 97-100.(In Chinese)

[3] F.Q. Liu, Medium Filtering Methods and Equipments. P.R.C. Patent ZL87100467.(1987).

[4] W.Y. Zhang, L.J. Xi, X.M. Chen etal, Working Principles and Features of Several Fiber Filter Equipments China Water Supply and Sewerage, Vol.19 (2003) No.6,P. 23-25.(In Chinese) 
[5] Ree-Ho Kim, Sangho Lee, Jinwoo Jeong, Reuse of Greywater and Rainwater Using Fiber Filter Media and Metal Membrane. Desalination, Vol.202 (2007) No.13,P. 326332.

[6] S.P. Yuan, M.L. Zhao and F.L. Yu, Experimental Study on Influence of Fiber Pulling Degree on Filtration, Industrial Water and Wastewater, Vol.37 (2005) No.4,P.71-73. (In Chinese)

[7] W.C. Cheng, Fiber Filter Equipments. P.R.C. Patent ZL98246416.9.(1998)

[8] W.S. Lyu, The Technical Parameter of the Self-adjusted Fiber-filtering Value Engineering, Vol.30 (2011) No.6,P.40.(in Chinese)

[9] F.Y. Cui, L.Tang and J. Xu, Experimental Study on Reuse Process of Car Washing Wastewater, Journal of Harbin Institute of Technology, Vol.37 (2005) No.3,P. 310-313.(In Chinese)

[10] S.Y. Nie, X.M. Lv and Ji, Li, A Comparative Study on Filtration Technology of Fiber and Quartz Sand, Journal of Environmental Engineering, Vol.6 (2012) No.1,P. 141-144.(In Chinese) 